Acta Cryst. (1970). B26, 1049

\title{
The Crystal Structure of Ethylenebis(biguanidine)nickel(II) Dichloride Monohydrate*
}

\author{
By Brad L. Holiant AND Richard E. Marsh \\ Arthur Amos Noyes Laboratory of Chemical Physics, California Institute of Technology, Pasadena, \\ California 91109 , U.S.A.
}

(Received 7 May 1969)

\begin{abstract}
The crystal structure of ethylenebis(biguanidine)nickel(II) dichloride monohydrate, $\mathrm{Ni}\left(\mathrm{C}_{6} \mathrm{H}_{16} \mathrm{~N}_{10}\right) \mathrm{Cl}_{2} . \mathrm{H}_{2} \mathrm{O}$, has been determined and refined on the basis of three-dimensional intensity data collected on an automated diffractometer. The crystals are monoclinic, space group $P 2_{1} / c$, with cell dimensions $a=6.911, b=11.678, c=18.055 \AA, \beta=101.39^{\circ}$; there are four molecules in the cell. The structure was determined by Patterson methods and refined by least-squares to an $R$ index of 0.048 and a goodness-of-fit of 1.11 for 2879 reflections of non-zero weight. The resulting standard deviations in the atomic positions are about $0.002-0.003 \AA$ for the $\mathrm{C}, \mathrm{N}$ and $\mathrm{O}$ atoms, $0.02-0.03 \AA$ for the $\mathrm{H}$ atoms and less than $0.001 \AA$ for $\mathrm{Ni}$ and $\mathrm{Cl}^{-}$.

The organic ligand is tetradentate and forms a square-planar array about the central nickel atom; the average $\mathrm{Ni}-\mathrm{N}$ distance is $1.865 \AA$. Chemically equivalent bonds are equal in length within experimental error, and the bond distances have been satisfactorily correlated with molecular-orbital and valencebond descriptions of the cation. All available hydrogen atoms are involved in hydrogen bonds to chloride ions or water molecules. An interesting feature is that, in spite of considerable double-bond character in the $\mathrm{C}-\mathrm{N}$ bonds, many of the hydrogen atoms are displaced appreciably from the plane of the cation toward the hydrogen-bond acceptors; the bonding about the nitrogen atoms thus becomes pyramidal.
\end{abstract}

\section{Introduction}

The crystal structure of the chloride of ethylenebis(biguanidine)nickel(II) (hereafter NiEBG) was studied in order to determine the geometry of the chelation of the ethylenebis(biguanidine) group. Cotton \& Wilkinson (1967) reviewed the properties of the silver analog, AgEBG, in which the EBG ligand is thought to be tetradentate. After we had begun this investigation, a brief report of the crystal structure of $\mathrm{CuEBG}$, which is isostructural with NiEBG, was published (Kunchur \& Mathew, 1966).

\section{Experimental}

Crystals of NiEBG, in the form of orange needles, were furnished by Professor B. D. Sharma (now at Oregon State University, Corvallis, Oregon). On heating in the air to about $150^{\circ} \mathrm{C}$, the crystals begin to shatter and turn opaque, presumably as the water of crystallization is driven out. At $260^{\circ}$ the crystals start to darken and at about $330^{\circ}$ they become dark brown. At $350^{\circ}$ they are black but remain solid, presumably reflecting strong hydrogen bonding. At room temperature they remained stable to X-ray exposure and to the atmosphere over the period of this investigation (three years). Apparently dehydration occurs to a small degree at room temperature since a few crystals in the original sample eventually became opaque. One such opaque

* Contribution No. 3847 from the Arthur Amos Noyes Laboratory. This investigation was supported in part by Research Grant GB-4775 from the National Science Foundation.

$\dagger$ Present address: Department of Chemistry, University of California, Berkeley, California 94704. crystal was found, by flotation, to have a density lower than that of a clear, intact crystal.

Oscillation and Weissenberg photographs about the needle $(a)$ axis showed the crystals to be monoclinic; absence of reflections $0 k 0$ with $k$ odd and $h 0 l$ with $l$ odd indicated the centrosymmetric space group $P 2_{1} / c$. Unit-cell dimensions were obtained from a leastsquares calculation based on $2 \theta$ measurements for 30 $0 \mathrm{kl}$ and $39 \mathrm{hol}$ reflections recorded on Weissenberg photographs prepared in a special camera in which the film is held in the asymmetric position. Absorption and eccentricity parameters were included in this calculation, but were found to be insignificant. The density was measured by flotation in a mixture of chloroform and dibromoethane. The crystal data are collected in Table 1.

\section{Table 1. Crystal data}

$$
\begin{array}{ll}
\mathrm{NiC}_{6} \mathrm{H}_{16} \mathrm{~N}_{10} \mathrm{Cl}_{2} \cdot \mathrm{H}_{2} \mathrm{O} & \text { F.W. 375.4 } \\
\text { Monoclinic } & \text { Space group } P 2_{1} / c \\
a=6.911(1) \AA & Z=4 \\
b=11.678(1) & F(000)=763.2 \\
c=18.055(2) & D_{m}=1.735 \mathrm{~g} . \mathrm{cm}^{-3} \\
\beta=101.39(1)^{\circ} & D_{x}=1.748 \mathrm{~g} \cdot \mathrm{cm}^{-3} \\
\left(\lambda \mathrm{Cu} K \alpha=1.5418 \AA ; \lambda \mathrm{Cu} K \alpha_{1}=1.5404 \AA\right)
\end{array}
$$

Preliminary intensity data were estimated visually from zero-level Weissenberg photographs about the $a$ axis. A Patterson projection onto (100) was prepared, from which the $y$ and $z$ coordinates of the $\mathrm{Ni}$ and $\mathrm{Cl}$ atoms were derived; however, because of severe overlap, the remaining atoms could not be located on subsequent electron-density projections.

At this time, a Datex-automated General Electric diffractometer became available. A nearly cubic crystal

A C $26 B-1$ 
with edges about $0.1 \mathrm{~mm}$ in length was mounted along the $a$ axis and the intensities of all reflections (3087) out to $2 \theta=154^{\circ}$ were measured using nickel-filtered copper radiation and a $\theta-2 \theta$ scan technique. The scan rate was $1^{\circ}$ (in $2 \theta$ ) per minute; background was counted for 30 seconds on each side of the peak. The $0,0,14$ reflection was measured after every 15 reflections; no significant change in its intensity was noted. Variances $\sigma^{2}(I)$ were calculated on the basis of counting statistics, but included an extra term $(0.02 \Gamma)^{2}$. Intensities and their standard deviations were corrected for Lorentz and polarization factors, but not for absorption $(\mu R=0 \cdot 3)$. Reflections for which the background count was larger than the scan count were given zero intensity and weight.

\section{Determination and refinement of the structure}

The coordinates of the nickel and chlorine atoms were derived from the prominent vector peaks on a threedimensional Patterson map, and the lighter carbon, nitrogen, and oxygen atoms were located on a subsequent three-dimensional electron-density map. Structure factors calculated at this stage led to an $R$ index $(R=$ $\left.\sum|| F_{o}|-| F_{c}|| / \sum F_{o}\right)$ of 0.50 .

Refinement was begun with two least-squares cycles in which only the coordinates of the 20 heavier atoms were adjusted; the resulting $R$ index was $0 \cdot 19$. Anisotropic temperature factors for the $\mathrm{Ni}$ and $\mathrm{Cl}$ atoms and isotropic temperature factors for $\mathrm{C}, \mathrm{N}$ and $\mathrm{O}$ were then included in the refinement, and after two cycles $R$ dropped to $0 \cdot 11$. A difference map was then evaluated in the planes in which the hydrogen atoms were expected to lie; however, the positions of the hydrogen atoms were not clearly indicated. Therefore, preliminary coordinates for the hydrogen atoms of the $\mathrm{NH}$, $\mathrm{NH}_{2}$ and $\mathrm{CH}_{2}$ groups were calculated from the ex- pected geometries, assuming coplanarity of the NH and $\mathrm{NH}_{2}$ groups with the rest of the cation and tetrahedral $-\mathrm{CH}_{2}$ groups; the hydrogen atoms of the water molecule were placed on lines directed toward neighboring chloride ions. These coordinates were not allowed to vary in the next two least-squares cycles, in which anisotropic temperature factors were introduced for the $\mathrm{C}, \mathrm{N}$ and $\mathrm{O}$ atoms. The resulting $R$ index was 0.061 . A second difference map, with the hydrogen contributions omitted from the $F_{c}$ values $(R=0 \cdot 070)$, was then calculated; this time, the hydrogen atoms were clearly apparent.

In the final refinement stages, a total of 254 parameters - coordinates for all atoms, anisotropic temperature parameters for $\mathrm{Ni}, \mathrm{Cl}, \mathrm{N}, \mathrm{O}$ and $\mathrm{C}$, isotropic temperature parameters for $\mathrm{H}$, a scale factor and a secondary extinction parameter (Larson, 1967) - were allowed to shift. Because of storage limitations in the available computer, all these parameters could not be placed in a single matrix. During the first four leastsquares cycles, one matrix contained all coordinates and the isotropic temperature parameters while a second matrix contained the anisotropic temperature parameters, the scale factor, and the secondary extinction parameter. $R$ dropped to 0.049 ; however, the shifts in the parameters of some groups of atoms (one of the $\mathrm{CH}_{2}$ groups and all the $\mathrm{NH}_{2}$ groups) remained large compared with their standard deviations. In the final two least-squares cycles, these recalcitrant parameters were all placed in one matrix; a second matrix contained all other heavy-atom coordinates and associated hydrogen parameters, except for the water molecule, while the anisotropic temperature parameters for the atoms in the second matrix, the parameters of the water molecule, and the scale and secondary extinction parameters were put into a third matrix. By dividing the parameters up in this manner we hoped to

Table 2. Final parameters of the heavy atoms, and their standard deviations (in parentheses)

All values have been multiplied by $10^{4}$. The expression for the anisotropic temperature factors is in the form

\begin{tabular}{|c|c|c|c|c|c|c|c|c|c|}
\hline \multicolumn{10}{|c|}{$\exp \left(-b_{11} h^{2}-b_{22} k^{2}-b_{33} l^{2}-b_{12} h k-b_{13} h l-b_{23} k l\right)$} \\
\hline & $x$ & $y$ & $z$ & $b_{11}$ & $b_{22}$ & $b_{33}$ & $b_{12}$ & $b_{13}$ & $b_{23}$ \\
\hline $\mathrm{Ni}$ & $2573(0.6)$ & $391(0 \cdot 3)$ & $88(0 \cdot 2)$ & $135(0 \cdot 9)$ & $30(0 \cdot 3)$ & $13(0 \cdot 1)$ & $0(0 \cdot 9)$ & $16(0 \cdot 5)$ & $-1(0 \cdot 3)$ \\
\hline $\mathrm{Cl}(1)$ & 2472 (1) & $-3615(0 \cdot 5)$ & $-2755(0 \cdot 3)$ & $219(2)$ & $50(0 \cdot 5)$ & $25(0 \cdot 2)$ & $-7(2)$ & $23(1)$ & $-22(0.5)$ \\
\hline $\mathrm{Cl}(2)$ & 3339 (1) & $-290(0.5)$ & $-3463(0 \cdot 3)$ & 377 (2) & $46(0.5)$ & $18(0 \cdot 2)$ & $-47(2)$ & $20(1)$ & $11(0.5)$ \\
\hline$N(1)$ & $2895(3)$ & 788 (2) & $1102(1)$ & $192(5)$ & 37 (1) & $15(1)$ & $-3(4)$ & 24 (3) & $6(1)$ \\
\hline$C(1)$ & 3377 (3) & 1751 (2) & $1428(1)$ & $137(6)$ & $43(2)$ & $15(1)$ & $10(5)$ & $18(3)$ & $-3(2)$ \\
\hline$N(2)$ & 3601 (4) & $1937(2)$ & $2182(1)$ & $270(7)$ & $57(2)$ & $15(1)$ & $-28(6)$ & 20 (3) & $-7(2)$ \\
\hline$N(3)$ & 3635 (3) & $2708(2)$ & $1020(1)$ & 207 (6) & 34 (1) & 17 (1) & $-13(4)$ & $19(3)$ & $-9(1)$ \\
\hline$C(2)$ & 3318 (3) & $2798(2)$ & 244 (1) & $146(6)$ & $34(2)$ & 19 (1) & $-3(5)$ & $26(3)$ & 1 (2) \\
\hline $\mathrm{N}(4)$ & 3483 (4) & 3875 (2) & $0(1)$ & 299 (7) & 34 (1) & 20 (1) & $-31(5)$ & 37 (4) & $-4(2)$ \\
\hline$N(5)$ & 2968 (3) & 1907 (1) & $-186(1)$ & $160(5)$ & 37 (1) & $14(1)$ & $4(4)$ & $14(3)$ & $0(1)$ \\
\hline$C(3)$ & 2588 (5) & $2112(2)$ & -1007 (1) & $256(8)$ & $43(2)$ & 17 (1) & $-17(6)$ & $28(4)$ & $6(2)$ \\
\hline$C(4)$ & 2695 (4) & 994 (2) & $-1417(1)$ & $190(7)$ & 46 (2) & $16(1)$ & $-0(6)$ & $33(4)$ & $2(2)$ \\
\hline$N(6)$ & 2259 (3) & 40 (1) & -941 (1) & $147(5)$ & 35 (1) & $16(1)$ & 3 (4) & $20(3)$ & $-2(1)$ \\
\hline$C(5)$ & 1909 (3) & -948 (2) & -1265 (1) & $140(6)$ & $42(2)$ & 19 (1) & $17(5)$ & $20(3)$ & $-7(2)$ \\
\hline$N(7)$ & $1752(4)$ & $-1137(2)$ & -2007 (1) & $307(8)$ & 48 (2) & $18(1)$ & 1 (6) & 43 (4) & $-15(2)$ \\
\hline N(8) & $1637(3)$ & $-1921(2)$ & $-863(1)$ & $193(5)$ & 32 (1) & $20(1)$ & $-1(4)$ & 22 (3) & $-8(1)$ \\
\hline C(6) & $1813(3)$ & $-2008(2)$ & $-97(1)$ & $130(6)$ & 37 (2) & 22 (1) & $13(5)$ & 21 (3) & $1(2)$ \\
\hline$N(9)$ & $1523(4)$ & $-3075(2)$ & $146(1)$ & $266(7)$ & $35(2)$ & 29 (1) & $1(5)$ & $25(4)$ & $7(2)$ \\
\hline$N(10)$ & $2173(3)$ & $-1124(2)$ & $335(1)$ & $180(5)$ & 38 (1) & 17 (1) & $-6(4)$ & $20(3)$ & 4 (1) \\
\hline & $1242(5)$ & $-4492(2)$ & $-1257(1)$ & 373 (9) & $122(3)$ & 27 (1) & $-84(8)$ & $54(4)$ & $-24(2)$ \\
\hline
\end{tabular}


include the most highly-interacting parameters within the same matrix and thus to speed convergence. The parameter shifts indeed settled down, the largest shift (the $x$ coordinate of a water hydrogen atom) being 0.23

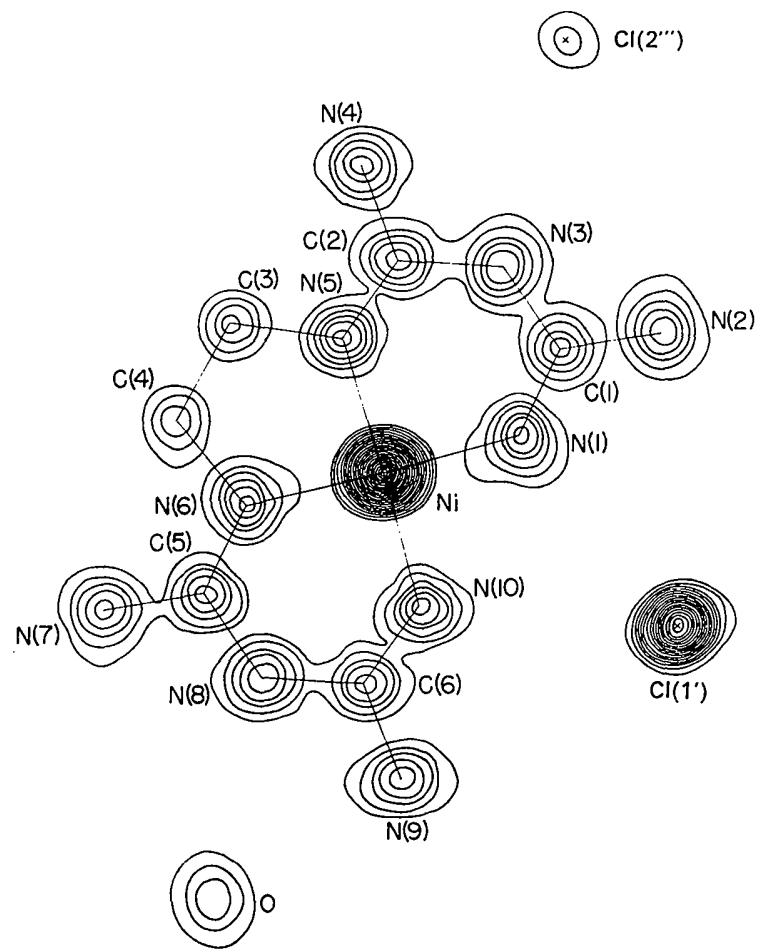

Fig. 1. Final electron density evaluated in the plane of the cation. Contours are drawn at $2,4,6, \ldots$, e. $\AA^{-3}$.

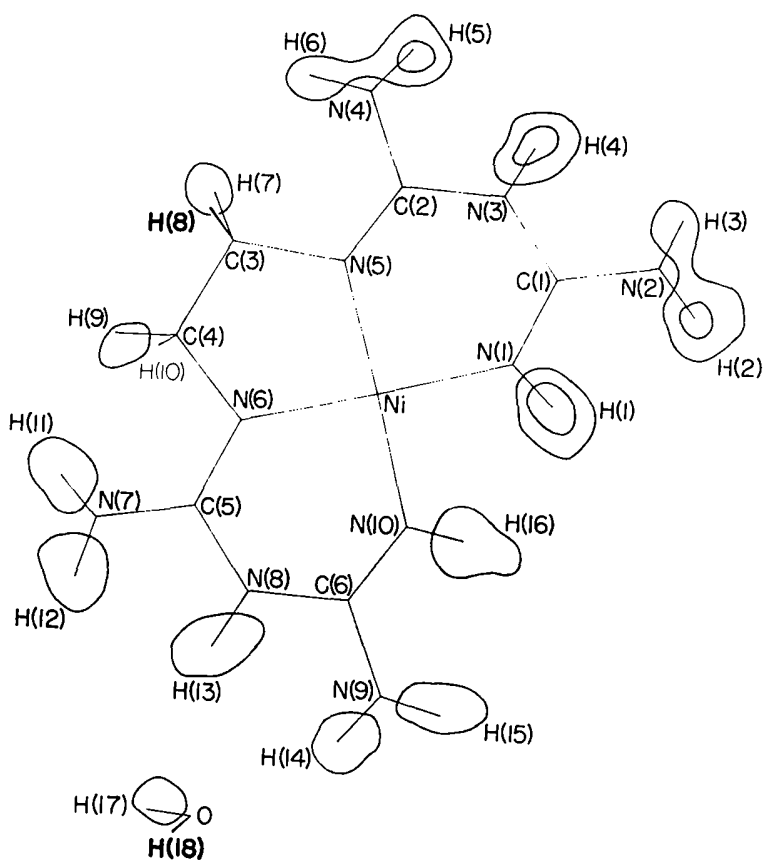

Fig. 2. Final difference map evaluated in the plane of the cation. Contours are drawn at 0.2 and $0.4 \mathrm{e} . \AA^{-3}$. times its standard deviation. Refinement was considered complete. Of the 3087 recorded intensities, 2879 were non-zero and were included in the leastsquares sums and the $R$ index. The final $R$ index was 0.048 and the goodness-of-fit, $\left[\sum w\left(F_{o}^{2}-F_{c}^{2}\right)^{2} / m-s\right]^{1 / 2}$, was $1 \cdot 11$. Tables 2 and 3 give the final atomic parameters and their standard deviations, and the structure factors are listed in Table 4. An electron-density map through the plane of the cation, calculated at the conclusion of the refinement, is shown in Fig. 1 ; the corresponding difference map, in which the contributions of the hydrogen atoms were omitted from the $F_{c}$ values, is shown in Fig. 2.

Table 3. Final parameters of the hydrogen atoms, and their standard deviations (in parentheses)

Values for the coordinates have been multiplied by $10^{3}$.

\begin{tabular}{lrrrr} 
& $\boldsymbol{x}$ & \multicolumn{1}{c}{$\boldsymbol{y}$} & \multicolumn{1}{c}{$z$} & \multicolumn{1}{c}{$\boldsymbol{B}$} \\
$\mathrm{H}(1)$ & $280(3)$ & $29(2)$ & $141(1)$ & $2 \cdot 8(0 \cdot 5)$ \\
$\mathrm{H}(2)$ & $368(5)$ & $138(3)$ & $244(2)$ & $6 \cdot 0(0 \cdot 9)$ \\
$\mathrm{H}(3)$ & $444(4)$ & $251(2)$ & $237(1)$ & $4 \cdot 1(0 \cdot 7)$ \\
$\mathrm{H}(4)$ & $370(4)$ & $330(2)$ & $123(1)$ & $4 \cdot 5(0 \cdot 6)$ \\
$\mathrm{H}(5)$ & $353(4)$ & $438(2)$ & $32(2)$ & $4 \cdot 4(0 \cdot 7)$ \\
$\mathrm{H}(6)$ & $308(4)$ & $405(2)$ & $-47(2)$ & $4 \cdot 6(0 \cdot 7)$ \\
$\mathrm{H}(7)$ & $352(4)$ & $265(2)$ & $-116(1)$ & $4 \cdot 6(0 \cdot 6)$ \\
$\mathrm{H}(8)$ & $129(4)$ & $246(2)$ & $-119(1)$ & $4 \cdot 0(0 \cdot 6)$ \\
$\mathrm{H}(9)$ & $179(4)$ & $101(2)$ & $-188(1)$ & $3 \cdot 3(0 \cdot 6)$ \\
$\mathrm{H}(10)$ & $406(4)$ & $88(2)$ & $-154(1)$ & $4 \cdot 5(0 \cdot 7)$ \\
$\mathrm{H}(11)$ & $219(4)$ & $-65(2)$ & $-227(1)$ & $3 \cdot 9(0 \cdot 7)$ \\
$\mathrm{H}(12)$ & $168(4)$ & $-184(2)$ & $-215(1)$ & $4 \cdot 2(0 \cdot 7)$ \\
$\mathrm{H}(13)$ & $143(4)$ & $-256(2)$ & $-110(1)$ & $3 \cdot 9(0 \cdot 6)$ \\
$\mathrm{H}(14)$ & $153(4)$ & $-361(2)$ & $-17(1)$ & $5 \cdot 1(0 \cdot 7)$ \\
$\mathrm{H}(15)$ & $197(4)$ & $-327(2)$ & $61(2)$ & $5 \cdot 2(0 \cdot 8)$ \\
$\mathrm{H}(16)$ & $217(3)$ & $-129(2)$ & $76(1)$ & $3 \cdot 7(0 \cdot 6)$ \\
$\mathrm{H}(17)$ & $159(5)$ & $-442(3)$ & $-160(2)$ & $6 \cdot 8(1 \cdot 2)$ \\
$\mathrm{H}(18)$ & $7(5)$ & $-469(3)$ & $-140(2)$ & $7 \cdot 1(1 \cdot 1)$
\end{tabular}

F. All calculations were carried out on an IBM 7094 computer using the $C R Y R M$ crystallographic computing system (Duchamp, 1964). Atomic form factors for $\mathrm{Ni}, \mathrm{Cl}^{-}, \mathrm{C}, \mathrm{N}$ and $\mathrm{O}$ were taken from International Tables for X-ray Crystallography (1962), the values for $\mathrm{Ni}$ being reduced by 3.2 electrons to take account of the real component of the anomalous dispersion; those for $\mathrm{H}$ were taken from Stewart, Davidson \& Simpson (1965). The quantity minimized in the least-squares calculations was $\sum w\left(F_{o}^{2}-F_{c}^{* 2}\right)^{2}$, where $F_{c}^{*}$ is as defined by equation (3) of Larson (1967), and weights $w$ were taken equal to the reciprocals of the variances $\sigma^{2}\left(F_{o}^{2}\right)$ (see Experimental).

\section{Discussion of the structure}

\section{Geometry of the cation}

A drawing of the NiEBG cation, including the covalent bond distances and angles involving the heavier atoms, is shown in Fig. 3. Distances and angles involving the hydrogen atoms are given in Table 5. The estimated standard deviations in the distances, as calculated from the uncertainties in the atomic coordinates (Tables 2 and 3 ), are about $0.002 \AA$ for the $\mathrm{Ni}-\mathrm{N}$ bonds, $0.003 \AA$ for the N-C and C-C bonds, $0.03 \AA$ for the 
Table 4. Observed and calculated structure factors

The four columns within each group contain the values of $L, 10 F_{\mathrm{obs}}, 10 \sigma\left(F_{\mathrm{obs}}\right)$, and $10 F_{\text {calc. }}$ Reflections indicated by asterisks $\left({ }^{*}\right)$ were given zero weight in the least-squares calculations. Standard deviations $\sigma(F)$ were calculated according to the expression

$$
\sigma(F)=\sqrt{F_{o}^{2}+\sigma \overline{\left(F_{o}^{2}\right)}}-F_{o},
$$

values of $\sigma\left(F_{o}^{2}\right)$ being obtained as described in Experimental.

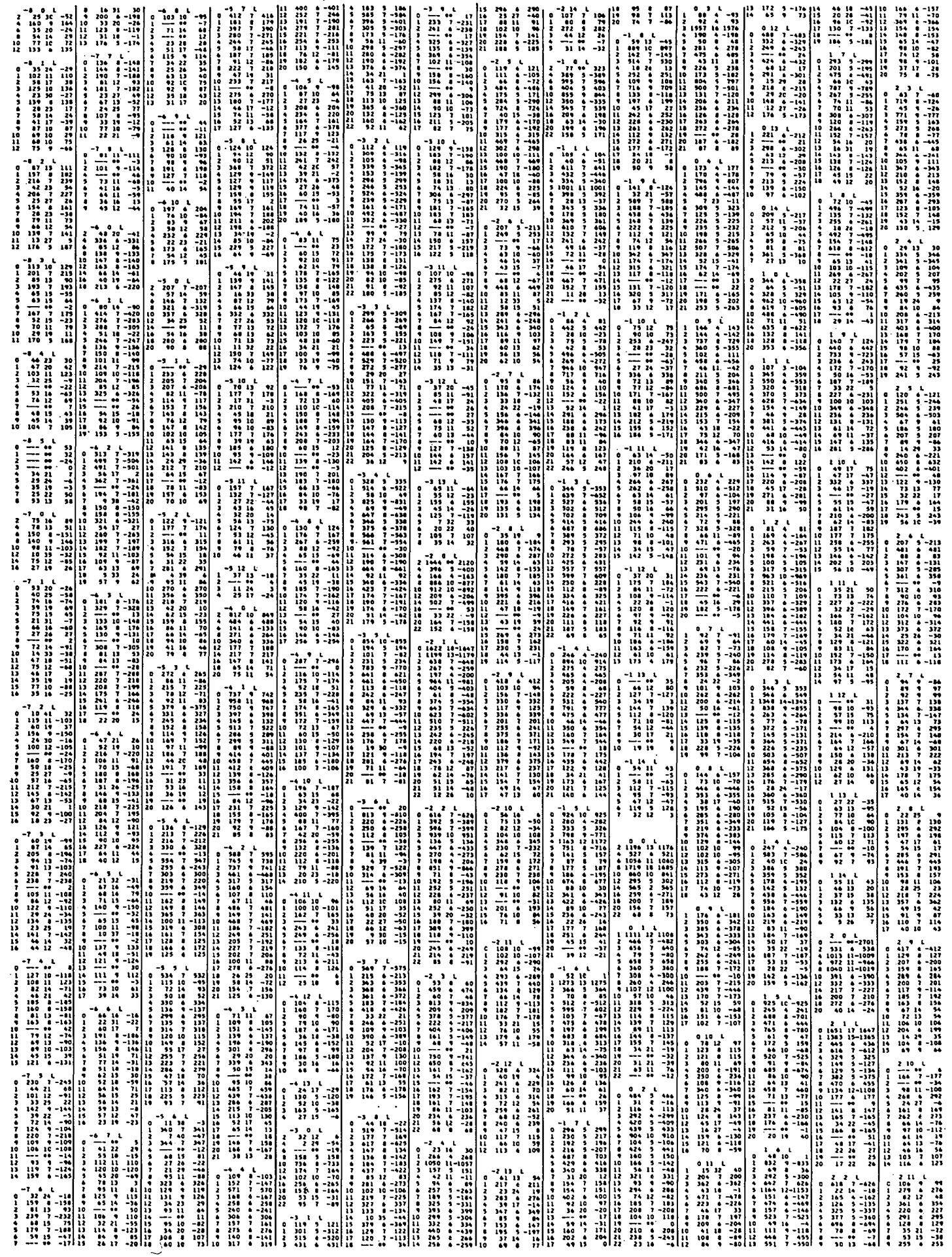


Table 4 (cont.)

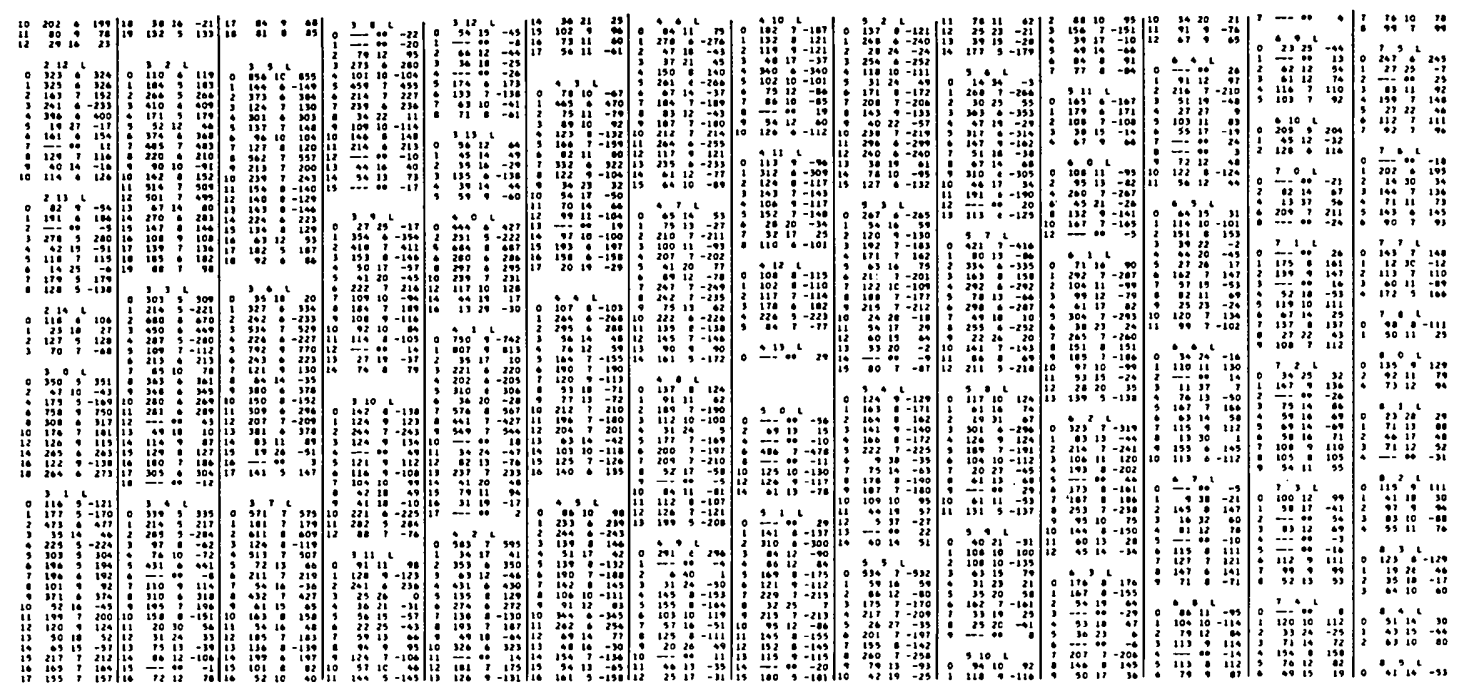

Table 5. Bond distances and angles involving hydrogen atoms

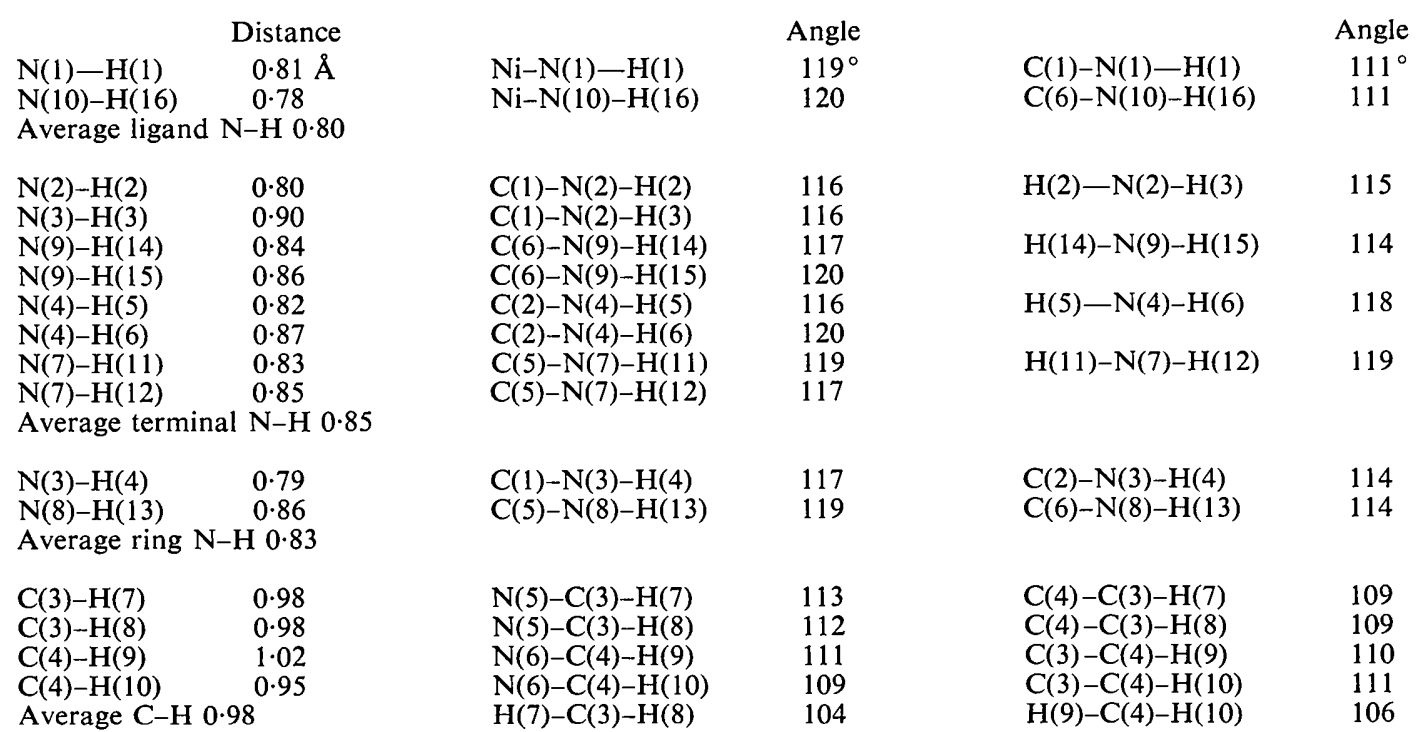

$\begin{array}{lr}\text { O-H(17) } & 0.70 \\ \text { O-H(18) } & 0.83 \\ \text { Average O-H } & 0.77\end{array}$

$\mathrm{H}(17)-\mathrm{O}-\mathrm{H}(18)$

$\mathrm{N}-\mathrm{H}$ and $\mathrm{C}-\mathrm{H}$ bonds and $0.04 \AA$ for the $\mathrm{O}-\mathrm{H}$ bonds; corresponding e.s.d.'s in the angles are about $0 \cdot 2^{\circ}$ when only heavier atoms are involved and about $2^{\circ}$ when hydrogen atoms are involved. Agreement between individual values expected to be chemically equivalent suggests that these standard deviations are reasonable. Except for distances involving the metal atom, the bond distances and angles agree with those reported by Kunchur \& Mathew (1966) for the copper compound within their experimental error, which appears to be about $0.04 \AA$. The average $\mathrm{Cu}-\mathrm{N}$ distance reported by them is $1.96 \AA$, nearly $0.1 \AA$ longer than our average $\mathrm{Ni}-\mathrm{N}$ distance of $1.865 \AA$.

The EBG group acts as a tetradentate ligand, wrapping itself around the nickel atom so as to form a square-planar array of $\mathrm{Ni}-\mathrm{N}$ bonds. The cation has approximate symmetry $C_{2}$, the twofold axis passing through the nickel atom and the mid-point of the $\mathrm{C}(3)-\mathrm{C}(4)$ bond. Deviations from symmetry $C_{2 v}(\mathrm{~mm} 2)$, which would require all the heavy atoms to be coplanar, 
are greater; they are associated principally with a twist about the $\mathrm{C}(3)-\mathrm{C}(4)$ bonc which permits a staggering of the methylene hydr., in atoms. Deviations from both symmetries are far larger for the hydrogen atoms of the $\mathrm{NH}$ and $\mathrm{NH}_{2}$ groups than for the other atoms; this feature will be discussed later.

The equation of the least-squares plane of the cation, calculated with each atom [except $\mathrm{C}(3)$ and $\mathrm{C}(4)$ ] weighted inversely proportional to the standard deviation in its $x$ coordinate, ${ }^{*}$ is given in Table 6 , together with the deviations of the individual atoms from this plane.

* If the atoms were indeed coplanar within experimental error, the weights used to calculate the 'best' plane should, of course, be taken inversely proportional to the squares of the standard deviations in the out-of-plane direction (which is approximately parallel to a). On the other hand, if the atoms were severely non-planar, it would probably be better to talk in terms of an 'average' plane, with all atoms weighted equally. In the present case, where the deviations from co-planarity are small but highly significant, we have taken weights intermediate between these two extremes. In any event, the principal effect of changing weights is merely to translate the plane along its normal, either toward or away from the nickel atom.
The bond distances can be satisfactorily explained on the basis of either valence-bond (VB) or Hückeltype molecular-orbital (MO) representations. The results are summarized in Table 7. In the VB treatment, bond numbers were calculated on the assumption that the canonical structures shown in Fig. 4 are the principal contributors to the resonance hybrid, structure $A$ contributing $50 \%$ and the five structures represented by $B$ and $C$ contributing $10 \%$. In the MO calculations, the coulomb integrals, $A(j)$, were chosen on the basis of electronegativity differences. $\dagger$ In both the VB and the MO calculations we have assumed that the methylene carbon atoms $\mathrm{C}(3)$ and $\mathrm{C}(4)$ are not a part of the aromatic system, although slight differences in the observed bond distances [compare, for example, $\mathrm{Ni}-\mathrm{N}(5)$ and $\mathrm{Ni}-\mathrm{N}(6)$ with $\mathrm{Ni}-\mathrm{N}(1)$ and $\mathrm{Ni}-\mathrm{N}(10)]$

$\dagger$ The coefficients of $B$ in the expressions for $A_{j}$ were taken cqual to the diffcrences $\left(x_{j}-x_{c}\right)$ between the electronegativity of atom $j$ and that of carbon as given by Pauling (1960); the value of $x$ for the ligand nitrogen atoms was increased, somewhat arbitrarily, by 0.5 to take account of the increased electronegativity of these atoms caused by the dative bonds they presumably form with the nickel atom.

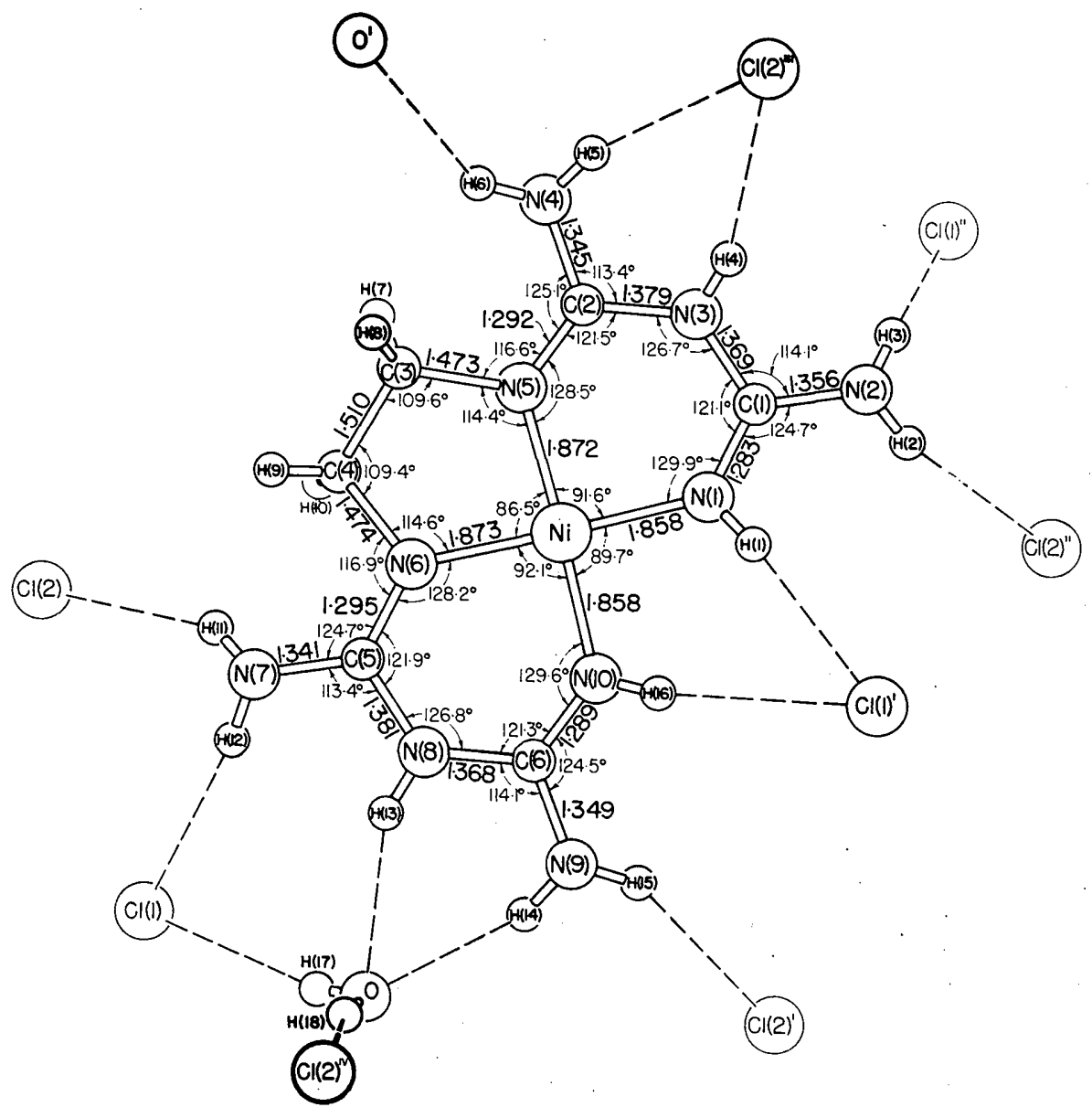

Fig. 3. Bond angles (deg) and bond distances $(\AA)$ within the cation. Dashed lines indicate hydrogen bonds. 
suggest significant double-bond character in the $\mathrm{N}(5)-\mathrm{C}(3)$ and $\mathrm{N}(6)-\mathrm{C}(4)$ bonds. The calibration values for relating the $\mathrm{C}-\mathrm{N}$ bond length to $\mathrm{VB}$ bond number (or MO bond order) were $1.47 \AA$ for a single bond, $1.24 \AA$ for a double bond, and $1.31 \AA$ for bond number 1.5 (see, for example, Marsh, Bierstedt \& Eichhorn, 1962). The single-bond $\mathrm{Ni}-\mathrm{N}$ distance was taken as 1.89 Å (Pauling, 1960).

An interesting, though perhaps not statistically valid, observation is the correlation between the observed values of the $\mathrm{N}-\mathrm{H}$ bond distances and the charges on the nitrogen atoms as derived by either the VB or MO representations. As the positive charge on the nitrogen atom increases the observed $\mathrm{N}-\mathrm{H}$ distance decreases, presumably reflecting the increased polarization of the electron cloud about the hydrogen atom. It is now well known that the position of a hydrogen atom as determined by X-ray diffraction measurements is greatly influenced by the electronegativity of the attached atom; in the present compound, for example, the observed $\mathrm{O}-\mathrm{H}$ distances are approximately $0 \cdot 2 \AA$ shorter than the $\mathrm{C}-\mathrm{H}$ distances.

Table 6. Least-squares plane of cation

Direction cosines relative to $\mathbf{a}, \mathbf{b}$ and $\mathbf{c}$ :

$$
\begin{gathered}
C_{1}=0.9788 \quad C_{2}=-0.1741 \quad C_{3}=-0.0883 \\
\text { Origin-to-plane distance }=1.658 \AA
\end{gathered}
$$

$\begin{array}{lrllrc} & \text { Deviation } & \text { Weight } & & \text { Deviation } & \text { Weight } \\ \mathrm{Ni} & -0.011 \AA & 1.00 & \mathrm{C}(3) & -0.176 \AA & 0.00 \\ \mathrm{~N}(1) & -0.035 & 0.20 & \mathrm{C}(4) & 0.189 & 0.00 \\ \mathrm{~N}(10) & -0.012 & 0.20 & & & \\ \mathrm{~N}(5) & -0.008 & 0.20 & \mathrm{H}(1) & -0.05 & 0.00 \\ \mathrm{~N}(6) & 0.012 & 0.20 & \mathrm{H}(16) & -0.05 & 0.00 \\ & & & \mathrm{H}(2) & 0.16 & 0.00 \\ \mathrm{C}(1) & 0.043 & 0.17 & \mathrm{H}(3) & 0.46 & 0.00 \\ \mathrm{C}(6) & -0.008 & 0.17 & \mathrm{H}(15) & 0.24 & 0.00 \\ \mathrm{C}(2) & -0.021 & 0.17 & \mathrm{H}(14) & 0.14 & 0.00 \\ \mathrm{C}(5) & 0.028 & 0.17 & \mathrm{H}(6) & -0.33 & 0.00 \\ & & & \mathrm{H}(5) & -0.21 & 0.00 \\ \mathrm{~N}(2) & 0.036 & 0.14 & \mathrm{H}(11) & 0.32 & 0.00 \\ \mathrm{~N}(9) & -0.026 & 0.14 & \mathrm{H}(12) & 0.20 & 0.00 \\ \mathrm{~N}(4) & -0.090 & 0.14 & & & \\ \mathrm{~N}(7) & 0.079 & 0.14 & \mathrm{H}(4) & -0.02 & 0.00 \\ & & & \mathrm{H}(13) & 0.00 & 0.00 \\ \mathrm{~N}(3) & 0.088 & 0.17 & \mathrm{H}(7) & 0.37 & 0.00 \\ \mathrm{~N}(8) & -0.022 & 0.17 & \mathrm{H}(8) & -1.10 & 0.00 \\ & & & \mathrm{H}(10) & 1.15 & 0.00 \\ & & & \mathrm{H}(9) & -0.35 & 0.00\end{array}$

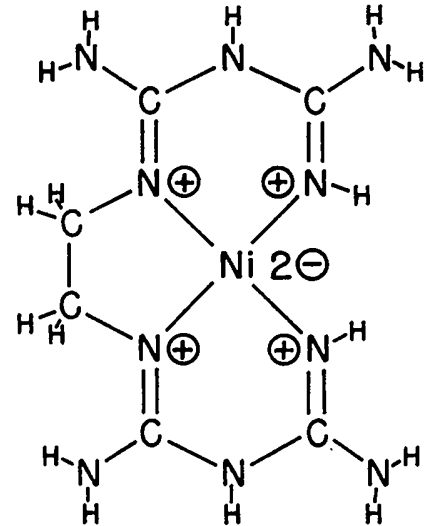

A. $50 \%$

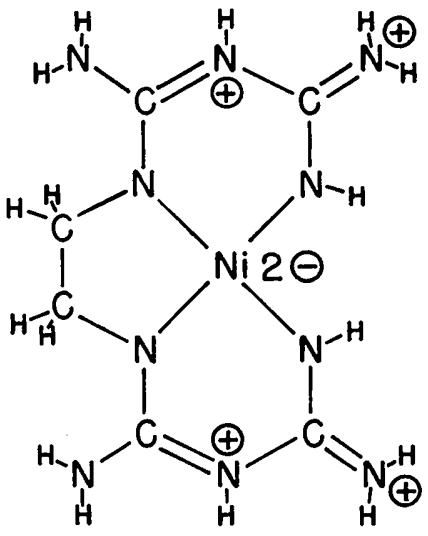

B. $40 \%$

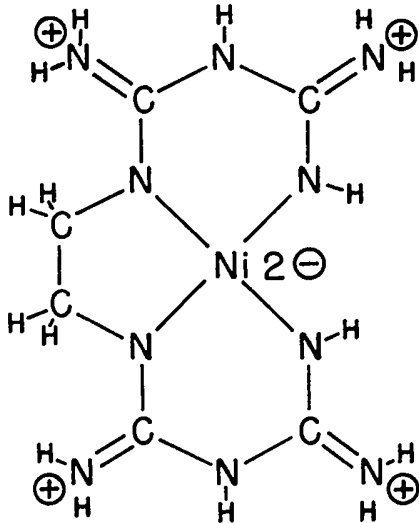

C. $10 \%$

(Four structures, 10)

Fig. 4. Canonical valence-bond structures of the $\mathrm{NiEBG}^{2+}$ cation and per cent contributions of each to the overall bonding scheme. 
The strong bonding between the nickel atom and the organic chelate is substantiated by both the relatively short $\mathrm{Ni}-\mathrm{N}$ distances and the high decomposition temperature.

\section{Temperature parameters}

The ellipsoids derived from the temperature-factor parameters of Table 2 are shown in Fig. 5. The temperature motions for the atoms of the cation are generally small, the largest corresponding to a root-mean-square displacement of $0.27 \AA$. In nearly all cases the direction of maximum displacement is perpendicular to the plane of the cation. The out-of-plane displacements are slightly greater for the peripheral atoms than for the nickel atom, suggesting a rigid-body motion of amplitude about $2^{\circ}$. There also appears to be a very small contribution of non-rigid-body motion; for example, the biguanidine carbon atoms $\mathrm{C}(1), \mathrm{C}(2), \mathrm{C}(5)$, and $\mathrm{C}(6)$ show slightly smaller r.m.s. displacements than do the ligand nitrogen atoms. The in-plane motions correspond to a rigid-body libration, about an axis passing through the nickel atom, also of approximately $2^{\circ}$ in amplitude.

The effects of these thermal motions on the observed bond distances are probably of the order of $0.005 \AA$ at most, and hence of marginal significance.

Table 7. Valence bond (VB) and molecular orbital (MO) treatments of the bonding in the (NiEBG) ${ }^{2+}$ cation

(1) Summary of assumptions in Hückel-type MO calculations

\begin{tabular}{lllc}
$\begin{array}{c}\text { Atom } \\
\text { type }(j)\end{array}$ & $\begin{array}{c}A j \\
\text { (Coulomb } \\
\text { integral) }\end{array}$ & \multicolumn{1}{c}{$\begin{array}{c}\text { Bond } \\
\text { type }(i j)\end{array}$} & $\begin{array}{c}B(i j) \\
\text { (Resonance } \\
\text { integral) }\end{array}$ \\
$\mathrm{C}$ & $A$ & C-ring N & $B$ \\
$\mathrm{Ni}$ & $A-0.7 B$ & C-ligand N & $2 \cdot 2 B$ \\
Ligand N & $A+B$ & C-terminal N & $1 \cdot 3 B$ \\
Ring N & $A+0.5 B$ & Ni-ligand N & $0.25 B$ \\
Terminal N & $A+0.5 B$ & (C-C & $B$ )
\end{tabular}

(2) Predicted VB bond numbers, MO bond orders, and bond lengths

\begin{tabular}{lclllc} 
& \multicolumn{2}{c}{ VB calculation } & \multicolumn{2}{c}{ MO calculation } \\
Bond & & Bond & \\
Bond type & number & $D(i j)$ & order & $D(i j)$ & $D(i j)_{\text {obs }}$ \\
C--ring N & 1.2 & $1.39 \AA$ & 1.37 & $1.38 \AA$ & $1.37 \AA$ \\
C-terminal N & 1.3 & 1.36 & 1.53 & 1.35 & 1.35 \\
C-ligand N & 1.5 & 1.31 & 1.75 & 1.30 & 1.29 \\
Ni-ligand N & 1.0 & 1.89 & 1.18 & 1.85 & 1.87
\end{tabular}

(3) Predicted charges on the atoms and the average observed $\mathrm{N}-\mathrm{H}$ distances

$\begin{array}{lccc} & & \begin{array}{c}\text { Average } \\ \mathrm{N}-\mathrm{H}\end{array} \\ \text { Atom type } & \mathrm{VB} & \mathrm{MO} & \text { distance } \\ \mathrm{C} & 0.0 & +0.15 & \\ \mathrm{Ni} & -2.0 & -2.10 & \\ \text { Ligand N } & +0.5 & +0.51 & 0.80 \AA \\ \text { Ring N } & +0.4 & +0.25 & 0.83 \\ \text { Terminal N } & +0.3 & +0.25 & 0.85\end{array}$
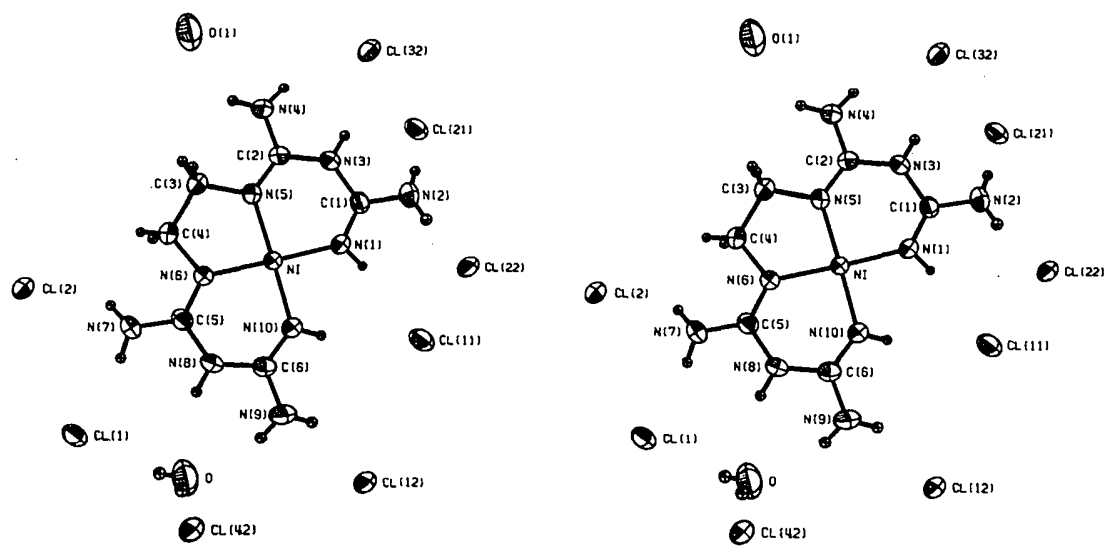

Fig. 5. Stereoscopic view (Johnson, 1965) of molecule along the $a$ axis; for the labeling of added hydrogen bond acceptors, see Fig. 3. 


\section{Hydrogen bonding and molecular packing}

As suggested by their high melting point, the crystals are held together by an extensive network of hydrogen bonding. This network is shown in Figs. 3, 5 and 6. All available hydrogen atoms form hydrogen bonds, either to chloride ions or to water molecules; the hydrogenbond distances are given in Table 8 .

\section{Table 8. Hydrogen bond distances}

$\begin{array}{ll}\begin{array}{l}\text { From } \\ \text { atom }\end{array} & \begin{array}{c}\text { to } \\ \text { atom }\end{array} \\ \mathrm{N}(7) & \mathrm{Cl}(1) \\ \mathrm{O} & \mathrm{Cl}(1) \\ \mathrm{N}(7) & \mathrm{Cl}(2) \\ \mathrm{N}(8) & \mathrm{O} \\ \mathrm{N}(9) & \mathrm{O} \\ \mathrm{N}(1) & \mathrm{Cl}(1) \\ \mathrm{N}(10) & \mathrm{Cl}(1) \\ \mathrm{N}(9) & \mathrm{Cl}(2) \\ \mathrm{N}(2) & \mathrm{Cl}(1) \\ \mathrm{N}(2) & \mathrm{Cl}(2) \\ \mathrm{N}(3) & \mathrm{Cl}(2) \\ \mathrm{N}(4) & \mathrm{Cl}(2) \\ \mathrm{O} & \mathrm{Cl}(2) \\ \mathrm{N}(4) & \mathrm{O}\end{array}$

\begin{tabular}{|c|c|c|c|}
\hline \multicolumn{3}{|c|}{ in molecule at } & Distance \\
\hline$x$ & $y$ & $z$ & $3 \cdot 272 \AA$ \\
\hline$x$ & $y$ & $z$ & $3 \cdot 161$ \\
\hline$x$ & $y$ & $z$ & $3 \cdot 199$ \\
\hline$x$ & $y$ & $z$ & $3 \cdot 086$ \\
\hline$x$ & $y$ & $z$ & $3 \cdot 000$ \\
\hline$x$ & $-\frac{1}{2}-y$ & $\frac{1}{2}+z$ & $3 \cdot 321$ \\
\hline$x$ & $-\frac{1}{2}-y$ & $\frac{1}{2}+z$ & $3 \cdot 427$ \\
\hline$x$ & $-\frac{1}{2}-y$ & $\frac{1}{2}+z$ & $3 \cdot 206$ \\
\hline$-x$ & $-y$ & $-z$ & $3 \cdot 341$ \\
\hline$-x$ & $-y$ & $-z$ & $3 \cdot 405$ \\
\hline$x$ & $\frac{1}{2}-y$ & $\frac{1}{2}+z$ & $3 \cdot 175$ \\
\hline$x$ & $\frac{1}{2}-y$ & $\frac{1}{2}+z$ & $3 \cdot 247$ \\
\hline$-x$ & $-\frac{1}{2}+y$ & $-\frac{1}{2}-z$ & $3 \cdot 242$ \\
\hline$x$ & $1+y$ & $z$ & $3 \cdot 131$ \\
\hline
\end{tabular}

As can be seen in Figs. 3 and 5, each cation is surrounded by a shell of acceptor atoms. These acceptor atoms are, in general, considerably displaced from the plane of the cation. We find it highly significant that, in every case, the hydrogen atom is also displaced out of the plane toward the acceptor atom, by amounts ranging up to nearly $0.5 \AA$ (see Table 6 ). Thus, although the bonds to the nitrogen atoms involve a large amount of double-bond character, the geometry about many of the nitrogen atoms is pyramidal rather than planar. An added consequence of the lack of planarity of N(7) and $\mathrm{N}(4)$ is the relief of steric interactions with the neighboring methylene groups.

The cations are stacked above one another along the $a$ axis (Fig. 6), the distance between neighbouring cations being about $3.3 \AA$. Individual contact distances are given in Table 9. Adjacent molecules, which are related by centers of symmetry, are stacked so as to minimize repulsive forces. Thus, the ethylene groups of one molecule fit into the cavity adjacent to $N(1)$ and $\mathrm{N}(10)$ of the adjacent molecule, and the closest intermolecular contacts are between atoms of differing electronegativities. The nearest neighbour of the nickel atom is a positively charged ligand nitrogen atom $\mathrm{N}(10)$. The shortest $\mathrm{Ni}-\mathrm{Ni}$ distances are 3.551 and $3.624 \AA$; by comparison, the $\mathrm{Cu}-\mathrm{Cu}$ distances in CuEBG (Kunchur \& Mathew, 1966) are 3.57 and $3.69 \AA$.

Table 9. Packing distances less than $3.5 \AA$

\begin{tabular}{|c|c|c|c|c|c|}
\hline $\begin{array}{l}\text { From } \\
\text { atom }\end{array}$ & $\begin{array}{l}\text { to } \\
\text { atom }\end{array}$ & \multicolumn{3}{|c|}{ in molecule at } & Distance \\
\hline $\mathrm{Ni}$ & $N(10)$ & $-x$ & $-y$ & $-z$ & $3.330 \AA$ \\
\hline$N(1)$ & $C(5)$ & $-x$ & $-y$ & $-z$ & $3 \cdot 396$ \\
\hline$N(1)$ & $\mathrm{N}(8)$ & $-x$ & $-y$ & $-z$ & $3 \cdot 348$ \\
\hline$C(1)$ & $N(8)$ & $-x$ & $-y$ & $-z$ & $3 \cdot 420$ \\
\hline$C(2)$ & $\mathrm{N}(9)$ & $-x$ & $-y$ & $-z$ & $3 \cdot 295$ \\
\hline$N(5)$ & $C(6)$ & $-x$ & $-y$ & $-z$ & $3 \cdot 443$ \\
\hline$N(5)$ & $\mathrm{N}(9)$ & $-x$ & $-y$ & $-z$ & 3.404 \\
\hline$C(1)$ & $C(5)$ & $1-x$ & $-y$ & $-z$ & 3.458 \\
\hline$C(1)$ & $\mathrm{N}(7)$ & $1-x$ & $-y$ & $-z$ & $3 \cdot 399$ \\
\hline $\mathrm{N}(2)$ & $N(7)$ & $1-x$ & $-y$ & $-z$ & $3 \cdot 418$ \\
\hline$N(3)$ & $\mathrm{N}(8)$ & $1-x$ & $-y$ & $-z$ & $3 \cdot 459$ \\
\hline
\end{tabular}

The Hückel-type MO calculations were carried out utilizing the program $H K 5$ developed by Professor J. D. Roberts.

Note added in proof: - We have recently learned of two other, independent $X$-ray investigations of the structure of this compound. Ward, Caughlan \& Smith (1970) collected 2228 reflections using Mo K $\alpha$ radiation and an XRD-5 diffractometer; their final $R$ index was 0.030 and their final atomic parameters are in excellent agreement with ours (Caughlan, private communication). Coghi, Mangia, Nardelli \& Pelizzi (1969) collected visual data using copper radiation and the Weissenberg technique; their final $R$ index was 0.092 for

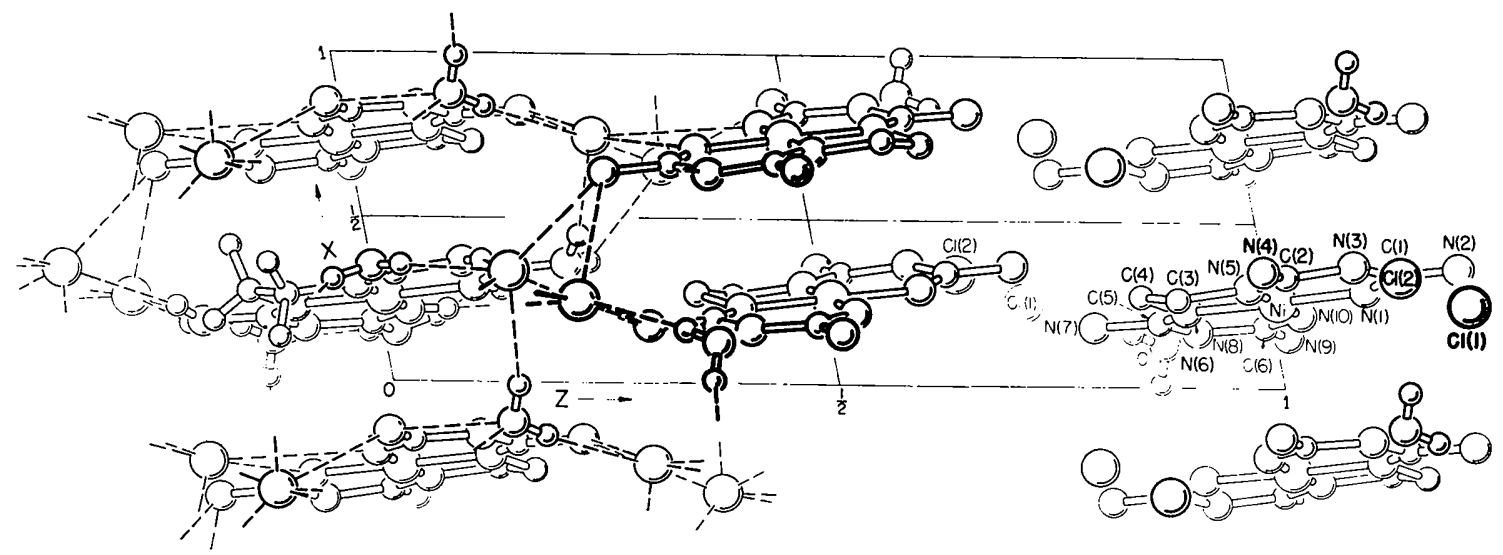

Fig. 6. Molecular packing viewed along the $b$ axis. Dashed lines indicate hydrogen bonds. The hydrogen atoms are shown only for the molecule whose coordinates are given in Table 2 . 
1970 observed reflections- Coghi et al. do not list the atomic parameters, but the over-all structure, including the bond distances and angles, is in reasonable agreement with our results.

Ward et al. describe their structure in a unit cell that is slightly more convenient than the one we have chosen $(a=6.905(5), b=11 \cdot 680(4), c=17.993(23) \AA$, $\beta=100 \cdot 68(10)^{\circ}$; space group, $\left.P 2_{1} / n\right)$.

We are grateful to Dr B. D. Sharma for providing the crystals and for advice and assistance in the early stages of the investigation, and to the National Science Foundation for financial support.

\section{References}

Coghi, Mangla, Nardelli \& Pelizzi(1969). Ric. Sci.39, 438. Cotton, F. A. \& Wilkinson, G. (1967). Advanced Inorganic Chemistry, 2nd ed., p. 1047. New York: Interscience.
Duchamp, D. J. (1964). Program and Abstracts, Amer. Cryst. Assoc. Meeting, Bozeman, Montana, Paper B-14, p. 29.

International Tables for X-ray Crystallography (1962). Vol. III, pp. 202-205. Birmingham: Kynoch Press.

JoHnson, C. K. (1965). ORTEP, A Fortran Thermal Ellipsoid Plot Program for Crystal Structure Illustrations. ORNL-3794, Oak Ridge National Laboratory, Oak Ridge, Tennessee, U.S.A.

Kunchur, N. R. \& Mathew, M. (1966). Chem. Comm. p. 86.

Larson, A. C. (1967). Acta Cryst. 23, 664.

MARSh, R. E., BIERSTEDT, R. \& EICHHORN, E. L. (1962). Acta Cryst. 15, 310.

Pauling, L. (1960). The Nature of the Chemical Bond, 3rd ed. Ithaca: Cornell Univ. Press.

Stewart, R. F., Davidson, E. R. \& Simpson, W. T. (1965). J. Chem. Phys. 42, 3175.

Ward, Caughlan \& Smith (1970). Program and Abstracts, ACA meeting, New Orleans, La.

Acta Cryst. (1970). B26, 1058

\title{
Refinement of the Crystal Structure of Iron Oxychloride
}

\author{
BY M.D. LIND \\ Science Center, North American Rockwell Corporation, Thousand Oaks, California 91360, U.S.A.
}

(Received 6 August 1969)

\begin{abstract}
The lattice constants and the positional parameters of crystals of the compound $\mathrm{FeOCl}$, the crystal structure of which was reported more than 35 years ago, have been redetermined from single-crystal $\mathrm{X}$-ray diffraction data. Except for corrections to the lattice constants and positional parameters, the previous description of the structure remains valid. The most probable space group is $P m n m$. The revised lattice constants, one of which differs substantially from those previously reported, are $a=$ $3.780 \pm 0.005, b=7.917 \pm 0.005$, and $c=3.302 \pm 0.005 \AA$. The positional and anisotropic thermal parameters were refined by the method of least-squares, with 294 non-zero diffractometer data, to a conventional $R=0.055$. Based on the refined parameters, the $\mathrm{Fe}^{3+}-\mathrm{O}^{2-}$ bond distances are $1.964 \pm 0.008$ and $2 \cdot 100 \pm 0 \cdot 010 \AA$, and the $\mathrm{Fe}^{3+}-\mathrm{Cl}^{-}$bond distance is $2 \cdot 368 \pm 0 \cdot 007 \AA$.
\end{abstract}

\section{Introduction}

The crystal structure of the compound $\mathrm{FeOCl}$, determined many years ago (Goldsztaub, 1934, 1935), was refined because a more accurate description of the structure was required for a proposed (Muir \& Wiedersich, 1967a) redetermination of the nuclear quadrupole moment of the $14.4 \mathrm{keV}$ level of ${ }^{57} \mathrm{Fe}\left(Q^{57 m} \mathrm{Fe}\right)$ from $\mathrm{FeOCl}$ data.

This investigation may be expected to aid in resolving the large discrepancies among values of $Q_{57 m} \mathrm{Fe}$ determined from data for other compounds [see discussions by Grant (1966) and by Artman, Muir \& Wiedersich (1968)] because $\mathrm{FeOCl}$ has certain features which make it especially suitable for determining this constant. An unusually large ferric ion nuclear quadrupole interaction is observed in the ${ }^{57} \mathrm{Fe}$ Mössbauer spectrum of $\mathrm{FeOCl}$ (Muir \& Wiedersich, 1967a). Furthermore, evaluation of the electric field gradient tensor at the ferric ion sites in the crystal, which is required in the analysis, is greatly facilitated by the small number of variable positional parameters in the $\mathrm{FeOCl}$ crystal structure and by the constraints imposed by the crystal symmetry and ferric ion site symmetry (see below).

In the proposed analysis, the particular step that requires very accurate structural data is a lattice sum calculation of the electric field gradient tensor components. The high sensitivity of such calculations to small variations in structural parameters has been discussed previously (Grant, 1966; Muir \& Wiedersich, 1967b; Artman et al., 1968).

\section{Experimental}

Crystals of $\mathrm{FeOCl}$ were grown by G. P. Espinosa of this Laboratory by a procedure similar to that reported 